\title{
DETERMINAÇÃO DAS ISOTERMAS E ADSORÇÃO DE GLICEROL EM CARVÃO ATIVADO DE OSSOS MODIFICADO COM ÁCIDO NÍTRICO NA PURIFICAÇÃO DE BIODIESEL
}

Fábio Henrique Oliveira da Silva ${ }^{1}$

Gredson Keiff Souza²

Marcelo Fernandes Vieira ${ }^{3}$

RESUMO: Neste trabalho foi realizado um estudo para avaliação do comportamento do equilíbrio de adsorção de glicerol em uma solução de glicerina PA em água destilada e glicerol no biodiesel produzido em laboratório. O biodiesel foi produzido à $30^{\circ} \mathrm{C}$ por transesterificação etílica de óleo de soja degomado catalisada por hidróxido de sódio com uma razão molar óleo:álcool de 1:7,5. O excesso de etanol foi retirado por evaporação e a glicerina bruta por decantação. O biodiesel resultante foi purificado por adsorção com carvão ativado de ossos bovinos modificado com ácido nítrico e por lavagem úmida e os resultados obtidos foram comparados. O óleo de soja e o biodiesel purificado foram caracterizados. Por meio de ensaios de equilíbrio obteve-se uma isoterma de adsorção para a solução 1 para a qual o modelo linear apresentou o melhor ajuste. No entanto, mesmo realizando seguidos experimentos para a solução de biodiesel não foi possível o ajuste dos modelos teóricos aos dados de equilíbrio.

${ }^{1}$ Graduando em Engenharia Química, Universidade Estadual de Maringá. e-mail: fabiohlopez@gmail.com

${ }^{2}$ Mestrando em Bioenergia, Universidade Estadual de Maringá. e-mail: gredsonkeiff@hotmail.com

${ }^{3}$ Professor Doutor no Curso de Engenharia Química, Universidade Estadual de Maringá. e-mail: marcelofvieira@hotmail.com 
Palavras-chave: Purificação. Biodiesel. Adsorção.

\section{INTRODUÇÃO}

Brasil está entre os maiores produtores e consumidores de biodiesel do mundo. Pioneiro mundial no uso de biocombustíveis. Cerca de $45 \%$ da energia e $18 \%$ dos combustíveis consumidos no Brasil já são renováveis. No resto do mundo, $86 \%$ da energia vêm de fontes energéticas não renováveis. O Brasil alcançou uma posição almejada por muitos países que buscam fontes renováveis de energia como alternativas estratégicas ao petróleo (ANP, 2012).

A reação de transesterificação é a etapa da conversão, propriamente dita, do óleo ou gordura, em biodiesel. Após esse processo, a massa reacional final é constituída de duas fases separáveis por decantação e/ou por centrifugação. A fase mais densa dessa massa e composta por glicerina bruta e a fase menos densa e constituída por uma mistura de ésteres etílicos e metílicos (Parente, 2003), sendo necessárias etapas posteriores de purificação da fase mais leve (biodiesel).

A técnica mais comum para a remoção de impurezas do biodiesel, tais como, resíduos de catalisadores, sais, álcool residual e glicerina, entre outros é a lavagem úmida. Devido a grande quantidade de efluentes produzidos nesse processo, novas metodologias de purificação têm sido propostas, dentre as quais se destaca a lavagem a seco, ou por adsorção (LOBO et al. 2009; FACCINI et al. 2011).

Nesse contexto os objetivos deste trabalho foram; caracterizar óleo de soja degomado, produzir biodiesel a partir desse óleo, realizar sua purificação por adsorção utilizando carvão ativado de ossos bovinos modificado com ácido nítrico e por lavagem úmida, caracterizar o biodiesel purificado e comparar os resultados entre os dois métodos de purificação. 


\section{MATERIAIS E MÉTODOS}

Nos experimentos foram utilizados, óleo de soja degomado fornecido pela cooperativa agroindustrial Cocamar de Maringá/PR, etanol anidro (99,8\% INPM), fornecido pela destilaria Renuka de São Pedro do Ivaí/PR, carvão ativado de ossos, fornecido pela Bonechar de Maringá/PR, hidróxido de sódio em micro pérolas, da marca Fmaia e ácido nítrico 65\%, da marca Fmaia.

A análise da composição de ácidos graxos foi realizada com o auxílio de um cromatógrafo da marca Varian, modelo CP - 3800, com detector de ionização em chama (DIC), contendo uma coluna capilar especifica para separação de ésteres (BP - X70 - SGE) de $30 \mathrm{~m} \times$ 0,25 mm. Realizou-se a técnica de derivatização de Hartmann e Lago (1973). Segundo esses autores, os componentes do óleo precisam ser convertidos em componentes de maior volatilidade, como por exemplo, em éteres etílicos.

Os ésteres foram obtidos por reação de transesterificação etílica de óleo de soja degomado de acordo com procedimento descrito por Gomes et al. (2011). Após o término da reação, a mistura reacional foi submetida a um evaporador rotativo sob vácuo de $600 \mathrm{mmHg}$ e temperatura em torno de $65^{\circ} \mathrm{C}$ para a recuperação do álcool em excesso. Após a evaporação do álcool, a mistura foi colocada em um funil de separação e deixada em repouso para a decantação da glicerina bruta e posterior separação das fases.

A determinação da massa específica do óleo de soja degomado e do biodiesel purificado por adsorção e lavagem úmida foi realizada no Departamento de Física na Universidade Estadual de Maringá em densímetro, marca Anton Paar, modelo DMA 5000. A temperatura de $25 \stackrel{\circ}{\circ}$.

Para o estudo do comportamento reológico do óleo foi utilizado um reômetro digital da marca Brookfield modelo DV-III. As análises foram realizadas na temperatura de $40{ }^{\circ} \mathrm{C}$. $\mathrm{O}$ spindle, para analise do óleo, foi SC 4-27 com velocidade rotacional entre 10 e $220 \mathrm{rpm}$. A viscosidade foi obtida para cada temperatura por meio de um ajuste linear nos gráficos de tensão de cisalhamento $\left(\right.$ dinas $\left./ \mathrm{cm}^{2}\right)$ por taxa de cisalhamento $\left(\mathrm{s}^{-1}\right)$. $\mathrm{O}$ valor obtido para $\mathrm{o}$ 


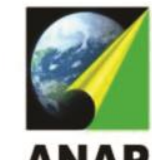

coeficiente angular da reta obtida corresponde à viscosidade da amostra na temperatura analisada.

A determinação do índice de acidez foi realizada conforme o método oficial da AOAC 940-28.

O teor de umidade foi determinado por meio do método Karl Fischer. Para isto, utilizou-se equipamento Karl Fischer, da marca Analyser, modelo Umidade controle KF-1000, pelo método ASTM D - 4377.

O teor de glicerol livre foi analisado baseado na metodologia modificada, pelo método oficial da AOCS para análise de glicerol livre em óleos e gorduras (Ca 14-56).

$\mathrm{Na}$ purificação por adsorção foi adicionado carvão ativado ao biodiesel na razão mássica biodiesel:carvão de 20:1. Os ensaios de adsorção foram realizados em uma incubadora Shaker da marca MARCONI, modelo MA 420, a 25ㄷ e 80 RPM na qual o carvão foi mantido em contato com o biodiesel em Erlenmeyers de $125 \mathrm{~mL}$ por $180 \pm 1 \mathrm{~min}$. Após esse tempo o carvão foi separado do biodiesel por filtração simples. A lavagem úmida do biodiesel não purificado foi realizada de acordo com a metodologia descrita por Faccini et al. (2011).

$\mathrm{Na}$ modificação química na superfície do adsorvente $5 \mathrm{~g}$ de carvão ativado foi adicionado em béquer de $50 \mathrm{~mL}$ com ácido nítrico $65 \%$. A mistura foi agitada por uma hora a 60 ㄷ. Em seguida, o ácido nítrico foi removido e a amostra de carvão modificado foi lavada com água destilada e colocada em estufa a $110{ }^{\circ} \mathrm{C}$ de acordo com Abdel-Nasser e ElHendawy (2003). Posteriormente foram realizados ensaios de adsorção, com carvões tratados seguindo a metodologia descrita acima utilizando diferentes soluções de ácido nítrico (1\%, 2\%, 3\%, 4\% e 65\%) e por apresentar resultados de remoção de glicerol elevados foi escolhido o tratamento com a solução ácida de menor concentração, (1\%) visando à redução de custos. Todos os ensaios de adsorção foram realizados em uma incubadora Shaker a $25^{\circ} \mathrm{C}$ e 80 RPM.

Foram realizados uma série experimentos para a determinação das isotermas de adsorção de glicerol em solução aquosa (solução 1) e outras de 3 para a determinação das 
isotermas de adsorção de glicerol no biodiesel (solução 2). No primeiro experimento para a solução 1 o procedimento experimental consistiu na preparação de uma solução de glicerina PA em água, a 0,2547\% (m/m), em solução 1:1, a qual foram preparadas 6 diluições em duplicata com água destilada de $20 \pm 0,0001 \mathrm{~g}$ cada, sendo as massas da solução 1:1 de (2; $5 ; 9 ; 12 ; 16 ; 20) \pm 0,0001 \mathrm{~g} /$ amostras de 1 a 6 . No segundo experimento foi preparada uma solução de glicerina PA em água de concentração $0,2717 \%(\mathrm{~m}: \mathrm{m})$, solução $1: 2$, qual foram preparadas 10 diluições em duplicata com água destilada de $20 \pm 0,0001 \mathrm{~g}$ cada, sendo as massas da solução $1: 2$ de $(20 ; 18 ; 16 ; 14 ; 12 ; 10 ; 8 ; 6 ; 4$ e 2) $\pm 0,0001$ gramas nas amostras de 1 a 10 respectivamente. Na etapa de determinação do teor de glicerol a concentração da solução titulante foi diluída em 4 vezes em relação ao valor habitual de $0,013 \mathrm{~g} / \mathrm{mL}$ de arsenito de sódio. Às amostras obtidas a partir desses procedimentos foram adicionados $7,5 \%$ em massa de adsorvente. O tempo de adsorção foi de $180 \pm 1 \mathrm{~min}$, após o qual, o carvão foi separado da solução por filtração simples e o teor de glicerol livre da solução resultante foi determinado para cada amostra.

No primeiro experimento para a solução 2 foram preparadas 5 amostras em duplicata de $20 \pm 0,0001 \mathrm{~g}$ da solução 2 e foram adicionados $(0,1 ; 0,2 ; 0,4 ; 0,6 ; 0,8) \pm 0,0001 \mathrm{~g}$ de adsorvente às amostras de 1 a 5 respectivamente. No segundo experimento foram preparadas 10 amostras em duplicata de $20 \pm 0,0001 \mathrm{~g}$ da solução 2 e foram adicionados $(0,9$; $0,8 ; 0,7 ; 0,6 ; 0,5 ; 0,4 ; 0,3 ; 0,2 ; 0,1 ; 0,05) \pm 0,0001 \mathrm{~g}$ de adsorvente às amostras de 1 a 10 respectivamente. No terceiro experimento foram preparadas 11 amostras em duplicata com o dobro da massa da solução 2, 40 $\pm 0,0001 \mathrm{~g}$, com o objetivo de aumentar a disponibilidade de glicerol para a adsorção. Foram adicionados $(1,1 ; 1,0 ; 0,9 ; 0,8 ; 0,7 ; 0,6 ; 0,5 ; 0,4 ; 0,3 ; 0,2$; $0,1) \pm 0,0001$ de adsorvente às amostras de 1 a 11 respectivamente. Na etapa de determinação do teor de glicerol a massa coletada de amostra a ser titulada foi dobrada, para 6g. Nos experimentos 2 e 3 dessa série a solução titulante foi diluída assim como foi realizado no segundo experimento para a solução 1. Não foi possível acrescentar glicerina PA a este biodiesel, pois esta decanta rapidamente, impossibilitando a realização das análises de teor de glicerol nessas condições. 
O tempo de adsorção foi de $180 \pm 1$ min para todos os experimentos de determinação das isotermas de adsorção, ao final do qual, o carvão foi separado por filtração simples e foi determinado o teor de glicerol livre no biodiesel purificado.

\section{RESULTADOS E DISCUSSÃO}

A composição de ácidos graxos do óleo de soja mostrou elevado teor de ácidos graxos insaturados tais como, oleico (30\%), linoleico (47,5\%) e linolênico (5,5\%). Estes valores estão de acordo com a literatura para esse tipo de óleo (Gomes et al., 2011). A tabela 1 apresenta as propriedades físico-químicas do óleo de soja degomado.

Tabela 1 - Propriedades físico-químicas do óleo de soja degomado

\begin{tabular}{cc}
\hline Propriedade & Resultado \\
\hline Massa Específica a $25^{\circ} \mathrm{C}\left(\mathrm{g} / \mathrm{cm}^{3}\right)$ & $0,9189 \pm 0,0007$ \\
Viscosidade a $40^{\circ} \mathrm{C}(\mathrm{cP})$ & 25,96 \\
Índice de Acidez $(\%)$ & $0,9131 \pm 0,0047$ \\
Teor de Umidade $(\%)$ & $0,1187 \pm 0,0045$ \\
Índice de Acidez $\left(\mathrm{mg} \mathrm{KOH}_{\mathrm{g} / \text { amostra }}\right)$ & $1,7348 \pm 0,0090$ \\
\hline
\end{tabular}

Os resultados obtidos demonstraram que o óleo de soja utilizado está dentro dos parâmetros físico-químicos necessários para a produção de biodiesel via etanólise alcalina, estando de acordo com os valores encontrados por (Murugesan, et al., 2009; Gomes et al., 2011). A Tabela 2 apresenta os dados da caracterização do biodiesel purificado por adsorção e lavagem, comparada às especificações para o biodiesel B100 brasileiro (ANP, 2012).

Tabela 2: Caracterização do biodiesel purificado por adsorção e lavagem especificações para o biodiesel B100 brasileiro estabelecidas pela ANP.

\begin{tabular}{cccc}
\hline Parâmetros & $\begin{array}{c}\text { Biodiesel } \\
\text { Adsorvido }\end{array}$ & $\begin{array}{c}\text { Biodiesel } \\
\text { Lavado }\end{array}$ & Limite ANP \\
\hline Teor de Ésteres (\%) & $94,95 \pm 1,13$ & $93,2 \pm 9,7$ & 96,5 mín. \\
Glicerol $(\%)$ & 0,0013 & $0,0056 \pm 0,0002$ & 0,02 máx. \\
Massa Específica a $25^{\circ} \mathrm{C}\left(\mathrm{g} / \mathrm{cm}^{3}\right)$ & 0,874 & 0.872 & $0,850-0,900$ \\
\hline
\end{tabular}


Viscosidade a Cinemática $40^{\circ} \mathrm{C}(\mathrm{cP})$ Índice de Acidez $\left(\mathrm{mg}_{\mathrm{KOH}} \mathrm{KOm}_{\mathrm{g} \text { astra }}\right)$ Teor de Umidade (\%)
3,42

$0,44 \pm 0,01$

$0,318 \pm 0,004$
4,07

$1,44 \pm 0,01$
$3,0-6,0$

0,5 máx. 0,5 máx.

O teor de umidade apresentou valores maiores para o biodiesel purificado por adsorção, no entanto, os analisados estão dentro das especificações da ANP. A viscosidade cinemática, o teor de glicerol livre e o índice de acidez apresentaram valores menores o que estabelecido pela ANP para o biodiesel purificado por adsorção, entretanto, o índice de acidez encontra-se acima do permitido para o biodiesel purificado por lavagem o que demonstra a potencialidade do processo de adsorção como método de purificação do biodiesel. $O$ teor de ésteres purificado por adsorção foi superior aquele obtido pela lavagem úmida, mas ainda levemente abaixo das normas da ANP, resultado esse que demonstra a necessidade de aprimoramento do método de adsorção, porém os resultados são promissores.

A Figura 1 corresponde aos dados de equilíbrio de adsorção para o primeiro experimento para determinação da isoterma de adsorção de glicerol para a solução 1 e a figura corresponde aos dados de equilíbrio de adsorção para o segundo experimento para a mesma solução. 


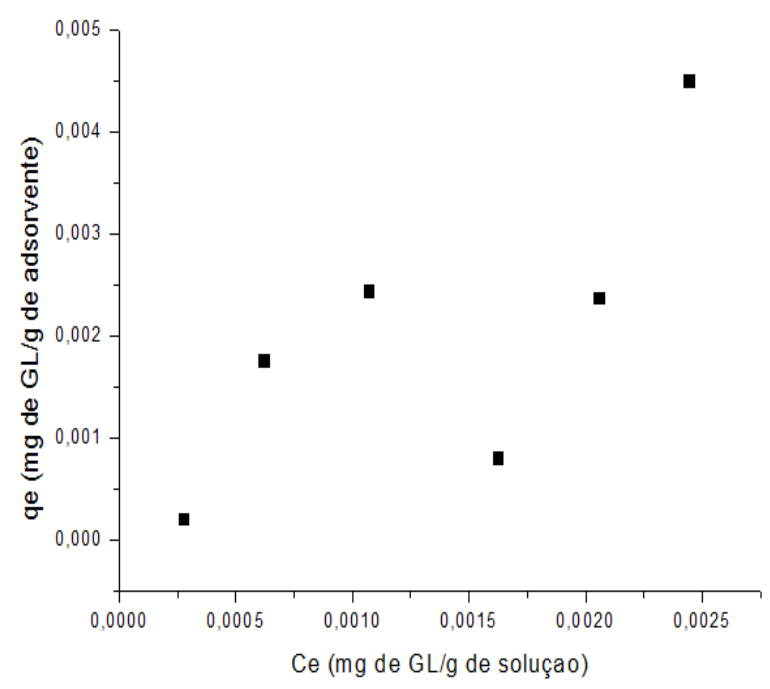

Figura 1: Dados de equilíbrio de adsorção do primeiro experimento para a determinação da isoterma de adsorção de glicerol para a solução 1 a $25^{\circ} \mathrm{C}$.

Como pode ser observado, os dados de equilíbrio mostrados na Figura 1 não representam a nenhuma isoterma, por não apresentarem um comportamento definido. Esse comportamento foi atribuído a erros experimentais causados principalmente pelo baixo número de pontos utilizados e a imprecisão do método titulométrico de determinação do teor de glicerol. Para minimizar a influência desses erros, no segundo experimento foram realizadas as mudanças descritas nos procedimentos. Foi observado também que aproximadamente $15 \%$ do volume da solução ficou retida no carvão após as etapas de adsorção e filtração. Para corrigir esse erro foi adotada equação 10 cálculo do teor de glicerol.

$G L_{,} \%=\frac{\left(\frac{G L_{1} m}{100} * M_{i} i-1,2785 * M c, i\right)}{M_{i} i} * 100$

Em que:

$G L, \%=$ Teor de glicerol em porcentagem mássica

$M, i=$ Massa total de da amostra i de biodiesel que foi purificado por adsorção.

$M c, i=$ Massa de carvão utilizada para a purificar a amostra i 


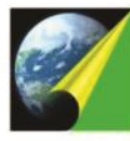

ANAP

$G L, i=$ Teor de glicerol em fração mássica determinado para o biodiesel através do calculo convencional.

E o valor 1,2785 é a massa de solução retida por unidade de massa de carvão adicionada, valor determinado experimentalmente.

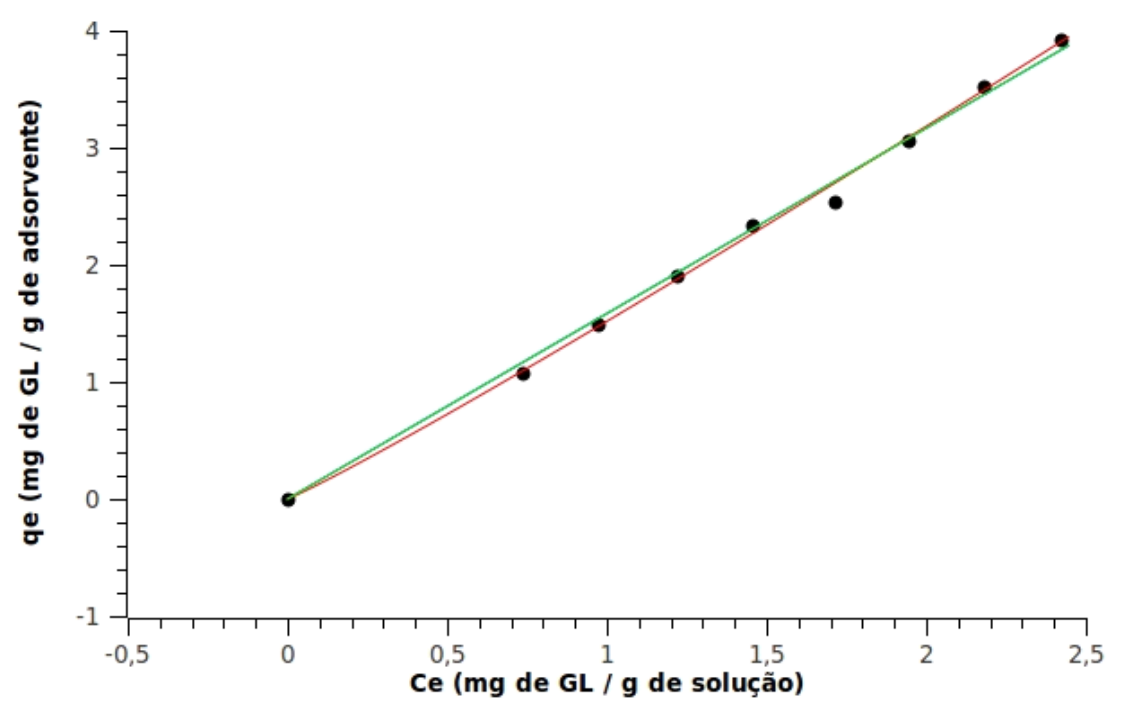

Figura 2: Isoterma de adsorção de glicerol para a solução 1 a $25^{\circ} \mathrm{C}$ e o ajuste dos dados aos modelos de adsorção de Langmuir, Freundlich e linear.

Pode-se verificar que as mudanças realizadas no método e na forma de calcular o teor de glicerol foram efetivas, pois, forneceram um conjunto de pontos com comportamento definido. A Figura 2 apresenta o ajuste dos modelos teóricos de adsorção de Langmuir, Freundlich e Linear aos dados do segundo experimento para a solução 1.

A seguir encontram-se as equações 2, 3 e 4 dos modelos de isotermas de Freundlich, Langmuir e Linear respectivamente, com a explicação de seus respectivos parâmetros e as unidades utilizadas nos ajustes.

$$
\begin{aligned}
& q=(K f * C)^{\left(\frac{1}{n}\right)} \\
& q=(q \max * B * C) /(1+B * C)
\end{aligned}
$$


$q=A * C$

$K f$ = Constante empírica dada em $g$ de solução/g de adsorvente

$n=$ Constante empírica adimensional.

$q=$ Quantidade adsorvida de glicerol no equilíbrio por unidade de massa de adsorvente dada em $\mathrm{mg}$ de glicerol $/ \mathrm{g}$ de adsorvente.

$C=$ Concentração de glicerol na solução em equilíbrio dada em $\mathrm{mg}$ de glicerol/g solução.

$B=$ Constante de Langmuir dada em $\mathrm{g} / \mathrm{mg}$.

$q \max =$ É o limite de saturação do adsorvente, que representa a sua máxima capacidade de adsorção em mg de adsorbato/g de adsorvente.

$A=$ É o coeficiente angular da reta, dado em g de solução/g de adsorvente.

Os valores dos parâmetros com seus respectivos erros e os coeficientes de correlação dos ajustes dos dados experimentais aos modelos podem ser encontrados na Tabela 3.

Tabela 3 - Parâmetros de equilíbrio de adsorção da solução 1.

\begin{tabular}{cccc}
\hline $\mathbf{R}^{2}$ & Parâmetros & Valor & Erro \\
\hline \multicolumn{4}{c}{ Freundlich } \\
0,997 & $\mathrm{n}($ admensional) & 0,936 & 0,029 \\
& $\mathrm{Kf}(\mathrm{g} / \mathrm{g})$ & 1,517 & 0,035 \\
\hline \multicolumn{4}{c}{ Langmuir } \\
\multirow{5}{*}{0,994} & $\mathrm{Qmax}(\mathrm{mg} / \mathrm{g})$ & 24037 & $9,38 \times 10^{8}$ \\
& $\mathrm{~B}(\mathrm{~g} / \mathrm{mg})$ & $6,587 \times 10^{-6}$ & $2,57 \times 10^{-2}$ \\
\hline \multirow{4}{*}{ Linear } \\
0,999 & $\mathrm{~A}(\mathrm{~g} / \mathrm{g})$ & 1,583 & 0,019 \\
\hline
\end{tabular}

Peereboon et al (2007) estudaram a adsorção de glicerol presente em solução aquosa a $25^{\circ} \mathrm{C}$ com dois tipos distintos de carvão ativado comerciais, ROX e 3310 carbon, numa faixa de concentração de 0 a $184 \mathrm{mg}$ de glicerol por grama de solução e obtiveram o melhor ajuste para o modelo de Langmuir para toda a faixa de concentração estudada, utilizado para 
a obtenção dos dados de equilíbrio a cromatografia líquida de alta eficiência. Os erros apresentados pelos parâmetros desse modelo no presente trabalho foram muito elevados, bem como, seu coeficiente de correlação foi o menor dentre os modelos o que demostra não ser esse adequado para a representação dos dados.

De acordo com McCabe (1993) a isoterma de Freundlich deve apresentar o parâmetro $n>1$, o que não foi verificado nos ajustes da Tabela 3. Dessa forma conclui-se que esse não é adequado para a representação dos dados de equilíbrio da solução 1.

Verificou-se, portanto, que o melhor ajuste para a solução 1 na faixa de concentração estudada é dado pelo modelo linear, pois este, além de apresentar o valor de $R^{2}$ próximo a 1 , também apresenta baixos valores para os erro do seu parâmetro, embora, haja a possibilidade de outros modelos como o de Langmuir, apresentado por Peereboon et al. (2007) se ajustarem melhor para uma faixa de concentração de glicerol maior, visto que o método de análise de glicerol utilizado neste trabalho não permite determinar a concentração de soluções de glicerol muito concentradas.

As Figuras 3, 4 e 5 correspondem aos dados de equilíbrio de adsorção para primeiro segundo e terceiro experimentos para determinação das isotermas de adsorção de glicerol para a solução 2 .

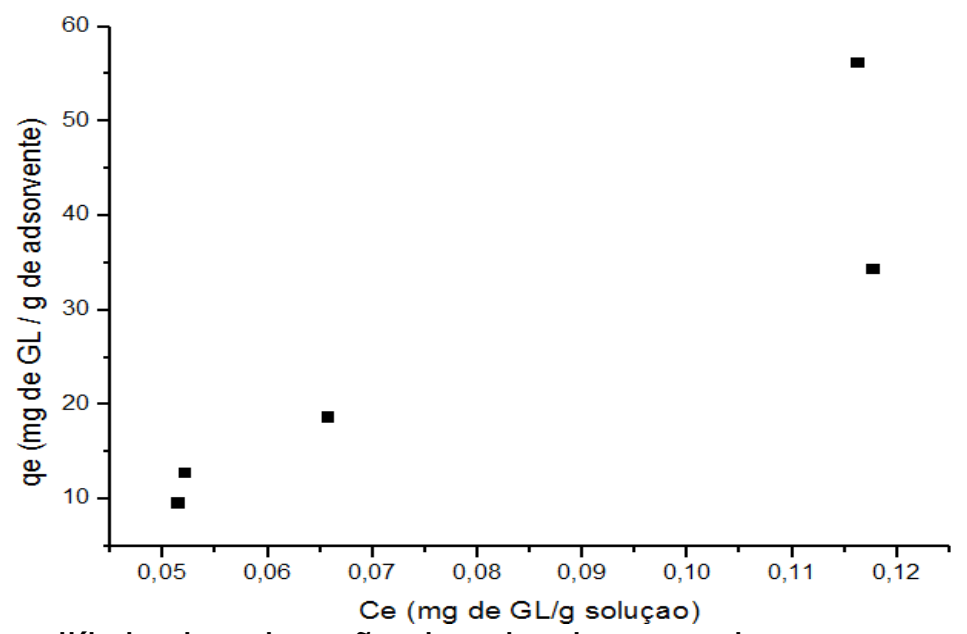

Figura 3: Dados de equilíbrio de adsorção do primeiro experimento para a determinação da isoterma de adsorção de glicerol para a solução 2 a $25^{\circ} \mathrm{C}$. 
Observa-se que os dados de equilíbrio mostrados na Figura 3 não apresentam comportamento definido. Vasques (2010) utilizou carvão ativado orgânico modificado com acido nítrico e biodiesel com 4,354 mg de glicerol por grama de biodiesel, e obteve isotermas de adsorção de glicerol a 20,30 e $40^{\circ} \mathrm{C}$ desfavoráveis. Devido ao método de produção de biodiesel utilizado neste trabalho apresentar alta eficiência de separação de glicerol por decantação, esse apresentou $0,41 \mathrm{mg}$ de glicerol por grama de biodiesel valor na ordem de 11 vezes menor do que o obtido por Vasques (2010), o que levou os erros aleatórios inerentes ao método titulométrico de determinação do teor de glicerol tornarem-se preponderantes à variação de concentração promovida pelo processo de adsorção. Para minimizar a influência dos erros experimentais, no segundo experimento para a solução 2 foram realizadas as mudanças descritas nos procedimentos. Os dados de equilíbrio obtidos a partir desse experimento encontram-se na Figura 5.

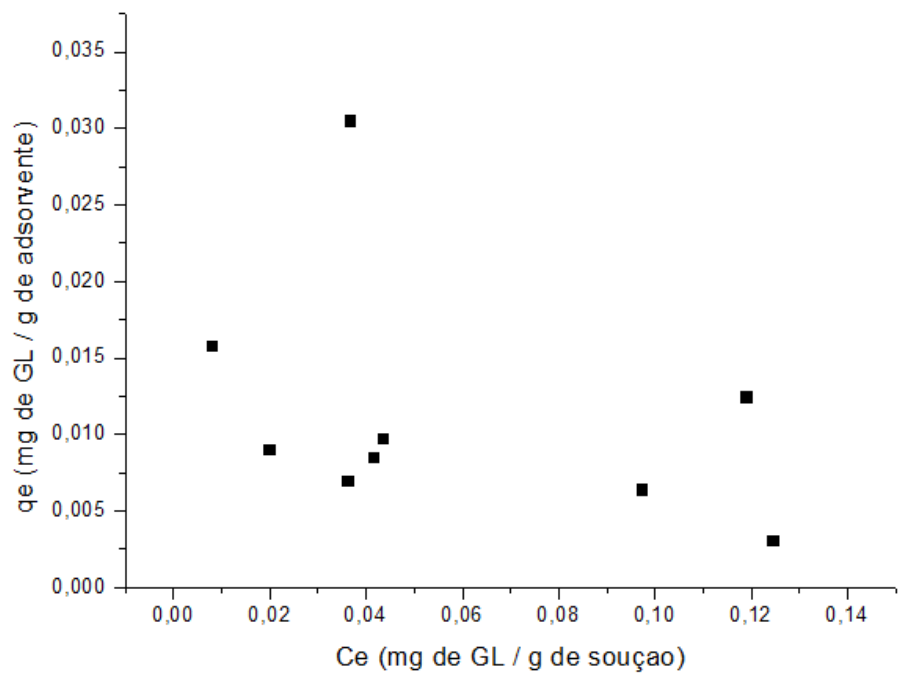

Figura 4: Dados de equilíbrio de adsorção do segundo experimento para a determinação da isoterma de adsorção de glicerol para a solução 2 a $25^{\circ} \mathrm{C}$.

A concentração de glicerol no biodiesel utilizado nesse experimento foi de $0,42 \mathrm{mg}$ de glicerol por grama de biodiesel, valor muito próximo do obtido no experimento 1 e, assim 
como na Figura 3, os pontos contidos Figura 4 não representam uma isoterma por não apresentarem um comportamento definido. No terceiro experimento mais adaptações nos métodos foram realizadas e encontram-se descritas nos procedimentos.

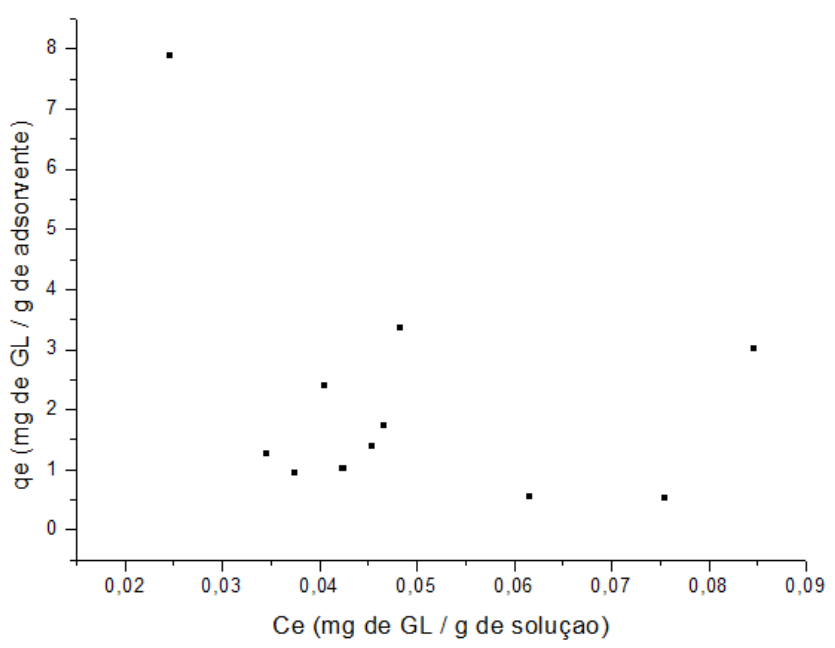

Figura 5: Dados de equilíbrio de adsorção do terceiro experimento para a determinação da isoterma de adsorção de glicerol para a solução 2 a $25^{\circ} \mathrm{C}$.

Assim como nas Figuras 3 e 4, os pontos referentes aos dados de equilíbrio mostrados na Figura 5 não representam uma isoterma. Desse modo não foi possível determinar qual modelo é mais adequado para representar os dados dispostos nas Figuras 3, 4 e 5.

A explicação para esse comportamento se deve principalmente a baixa precisão do método de determinação do teor de glicerol utilizado para a análise da solução 2 e mesmo a série de modificações realizadas no método não foram suficientes para adequá-lo às características da solução em estudo. Faccini et al. (2011) utilizaram biodiesel produzido por transesterificação alcalina de óleo de soja (metanol/KOH), utilizando como método de identificação do teor de glicerol a cromatografia em fase gasosa e obtiveram biodiesel bruto com 2,6 mg de glicerol por grama de biodiesel.

\section{CONCLUSÃO}


Os resultados obtidos demonstraram que o óleo de soja utilizado está dentro dos parâmetros físico-químicos necessários para a produção de biodiesel via etanólise alcalina, estando de acordo com os parâmetros encontrados por outros autores.

As propriedades físico-químicas do biodiesel purificado por adsorção, avaliadas por sua caracterização, apresentaram bons resultados quando comparados ao biodiesel purificado por lavagem, o que demonstra o potencial do método proposto.

A isoterma de adsorção para a solução 1 na faixa de concentração estudada segue 0 modelo linear com o coeficiente de correlação igual a 0,999 o que é condizente com o fato de ter sido utilizada uma solução diluída.

Não foi possível obter-se uma isoterma de adsorção para a solução 2 demonstrando que o método utilizado para a determinação do teor de glicerol livre não é adequado para a determinação dos dados de equilíbrio do biodiesel purificado por adsorção obtido neste trabalho.

\section{REFERÊNCIAS}

ABDEL-NASSER A e EL-HENDAWY. Influence of $\mathrm{HNO}_{3}$ Oxidation on the Structure and Adsorptive Properties of Corncob-Based Activated Carbon. Carbon, v. 41, p. 713 - 722 , 2003.

ANP - Agencia Nacional de Petróleo, Gás Natural e Biocombustível. Disponível em (http://www.anp.gov.br/). Acesso em 15/09/2012.

A.O.A.C. ASSOCIATION OF OFFICIAL ANALYTICAL CHEMISTS. Official Methods of Analysis of AOAC International. Food composition, additives, natural contaminants. 16. ed. v. 2. Gaithersburg: AOAC, 1997.

AOCS. ASSOCIATION OF OFFICIAL ANALYTICAL CHEMISTS. Official Methods and Recommended Practices of the American Oil Chemists' Society. Champaing, III.: AOCS. 2004

FACCINI C. S.; DA CUNHA M. E.; MORAES M. S. A.; KRAUSE L. C.; MANIQUE C. M.; RODRIGUES M. R. A.; BENVENUTTI E. V.; CARAMÃO E. B. (2011) Dry Washing in Biodiesel Purification: a Comparative Study of Adsorbents. Journal of the Brazilian Chemical Society, Vol. 22, No. 3, 558-563, 2011. 


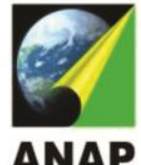

GOMES, M. C. S.; PEREIRA, N. C.; AROOYO, P. A. Biodiesel production from degummed soybean oil and glycerol removal using ceramic membrane. Journal of Membrane Science, v. 378, p. 453 - 461, 2011.

HARTMAN, L., LAGO, R.C.A. Rapid Preparation of Fatty Acids Methyl Esters. Laboratory Practice, London, v.22, p.475-476, 1973.

LÔBO, I. P.; FERREIRA, S. L. C.; CRUZ, R. S. Biodiesel: Parâmetros de Qualidade e Métodos Analíticos. Quim. Nova, Vol. 32, No. 6, 1596-1608, 2009.

McCABE, W. L.; SMITH, J. C.; HARRIOTT, P. Unit operations of chemical engineering. 5th ed., New York, McGraw-Hill, Inc. 1993.

MURUGESAN, A.; UMARANI, C.; CHINNUSAMY, T. R.; KRISHNAN, M.; SUBRAMANIAM, R.; NEDUZCHEZHAIN, N. Production and analysis of biodiesel from non-edible oils - A review. Renewable and Sustainable Energy Reviews, v. 13, p. 825-834, 2009.

PARENTE, EXPEDITO JOSÉ DE SÁ. Uma Aventura Tecnológica Num País Engraçado. 1. Ed. Fortaleza: 2013.

PEEREBOON, L.; KOENIGSKNCHT, B.; HUNTER, M.;JACKSON, J. E.;MILLER, D. J. Aqueous-phase adsorption of glycerol and propylene glycol onto activated carbon. Carbon, v 45, p. 579-586, 2007.

VASQUES. E. K., Adsorção de Glicerol, Mono e Di-glicerídeos Presentes no Biodiesel Produzido a Partir do Óleo de Soja. UFPR 2010. Dissertação (Mestrado em Tecnologia de Alimentos) - Universidade Federal do Paraná. 2010. 